\title{
Control of abnormal pressure to hydrocarbon migration \& accumulation-A Case Study on the lower assemblage of Yanchang formation in the middle area of western Ordos Basin
}

\author{
FAN Yuhai ${ }^{1,2, a}$, WANG Hui ${ }^{2, b}$, TAN Furong ${ }^{2, c}$ \\ ${ }^{1}$ School of Earth Science and Land and Resources, Chang'an University, Xi'an 710054,China \\ ${ }^{2}$ Geological Exploration Institute of Aerial Photogrammetry and Remote Sensing Bureau, Xi'an \\ 710199,China \\ a170269854@qq.com, bwanghui.rock@163.com, 'tanfurong1308@163.com
}

Keywords: in the west of Ordos Basin; lower assemblage of Yanchang Formation; abnormal pressure; hydrocarbon migration \& accumulation

Abstract: In this article the author use the datas of acoustic travel time, systematical analysising the abnormal pressure distribution obtained by equilibrium depth method in the lower assemblage of Yanchang formation 151 well bores in the middle area of western Ordos Basin, combined with the distribution patterns of hydrocarbon reservoir discovered in the researched region, the relationship between abnormal pressure and distributions of hydrocarbon reservoir discovered and also hydrocarbon migration $\&$ accumulation is disclosured. The study shows that the abnormal pressure is presented in each well of Chang 7 and Chang 8 oil-bearing formation in the researched region. The difference of abnormal pressure between Chang 7 and Chang 8 , usually about $8 \sim 12 \mathrm{MPa}$, is the principal dynamic power to make the migration of hydrocarbon downward. The hydrocarbon reservoir discovered is closely relative with the abnormal pressure, most of hydrocarbon reservoirs distribute in areas with high abnormal pressure difference on a background of low abnormal pressure difference between Chang 7 and Chang 8 .

\section{Introduction}

The study of abnormal pressure along the coast of Mexico has opened the prelude to the study of abnormal pressure in the world ${ }^{[1]}$. According to statistic results, there are more than 180 overpressure basins in the world, of which 160 basins are rich in hydrocarbon, abnormal high pressure fields account for 30 percent of the total fields of the world ${ }^{[2-5]}$. Surpressure has very important influences on hydrocarbon migration \&accumulation. Study of the relationship between abnormal pressure and distributions of hydrocarbon reservoir has great guide function for exploration drilling and exploration activity ${ }^{[6-10]}$.Based on systematical analysis of the abnormal pressure distribution obtained by equilibrium depth method ${ }^{[11]}$ in the lower assemblage of Yanchang formation in the middle area of western Ordos Basin, combined with the distribution patterns of hydrocarbon reservoir discovered in the researched region, the relationship between abnormal pressure and distributions of hydrocarbon reservoir discovered and also hydrocarbon migration $\&$ accumulation is disclosured.

\section{Location and Geological Setting of the Study Area}

The study area located the Yi Shan slope western centre zone of Ordos Basin, west adjacency of Tian Huan central depression (Figure 1). Late Triassic of Ordos Basin overallly perform the northeast slow, southwest steep south-west water body with gradually deepening dustpan-like shape, the study area located norther regions of in the western middle of basin at that time. Horizon of this study is mainly Chang 7 and Chang 8 oil-bearing formation. 


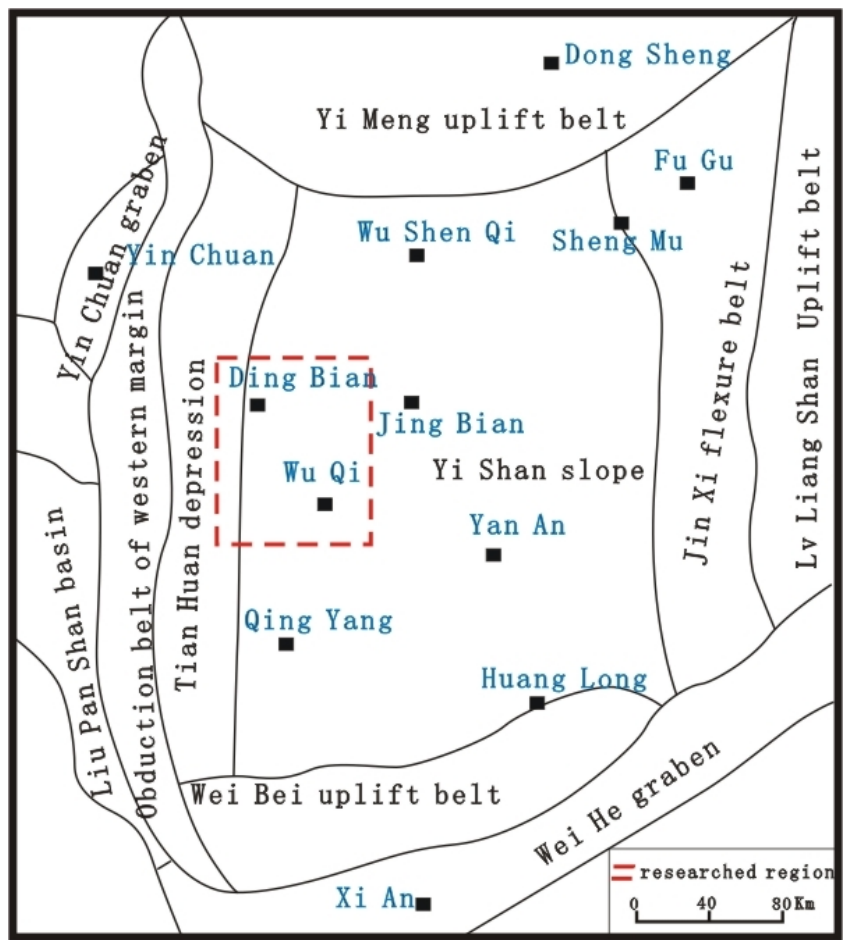

Fig.1 Tectonic location map of the researched region

\section{Distribution characteristics of Chang 7 and Chang 8 abnormal pressure of YanChang formation}

\section{Plane distribution characteristics of Chang 7 abnormal pressure}

Abnormal pressure of Chang 7 reservoir group in researched region is generally more than $8 \mathrm{MPa}$, most of the region is more than $16 \mathrm{MPa}$, in some areas (such as the Fengdikeng, Jiyuan, northwest of Tiebiancheng and southeast of Wu Qi) of more than 24MPa. Abnormal pressure as a whole has trend of gradually decreasing along the Northwest-Southeast from the middle to both sides (Figure 2).

\section{Plane distribution characteristics of Chang 8 abnormal pressure}

In the researched region, Chang 8 reservoir group compared with Chang 7, abnormal pressure is overall low, most regions is $12 \mathrm{MPa}$ below, abnormal pressure of in some areas (for example, Jiyuan, Southwest of tiebiancheng) excess $16 \mathrm{MPa}$ (Figure 3), mainly due to abnormal pressure of Chang 7 reservoir group. 


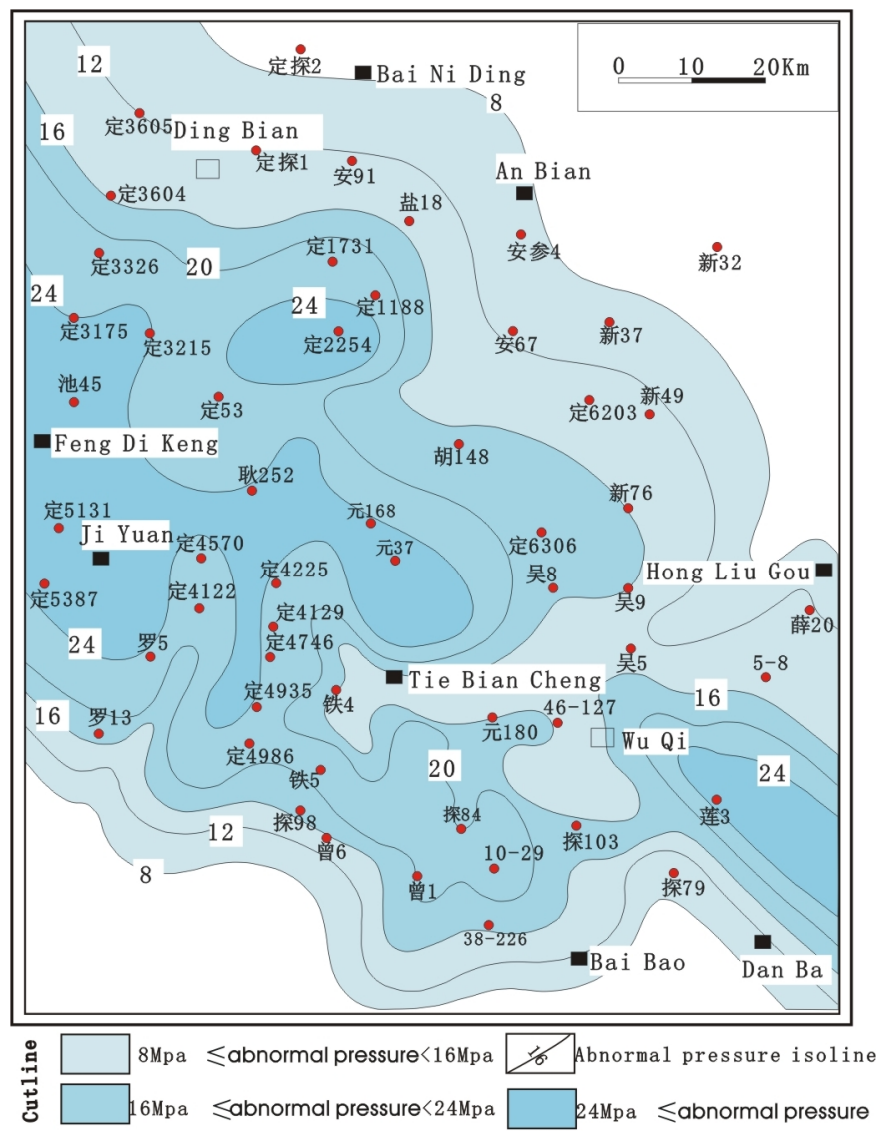

Fig.2 Distribution map of abnormal pressure of Chang 7 oil-bearing formation in the researched region

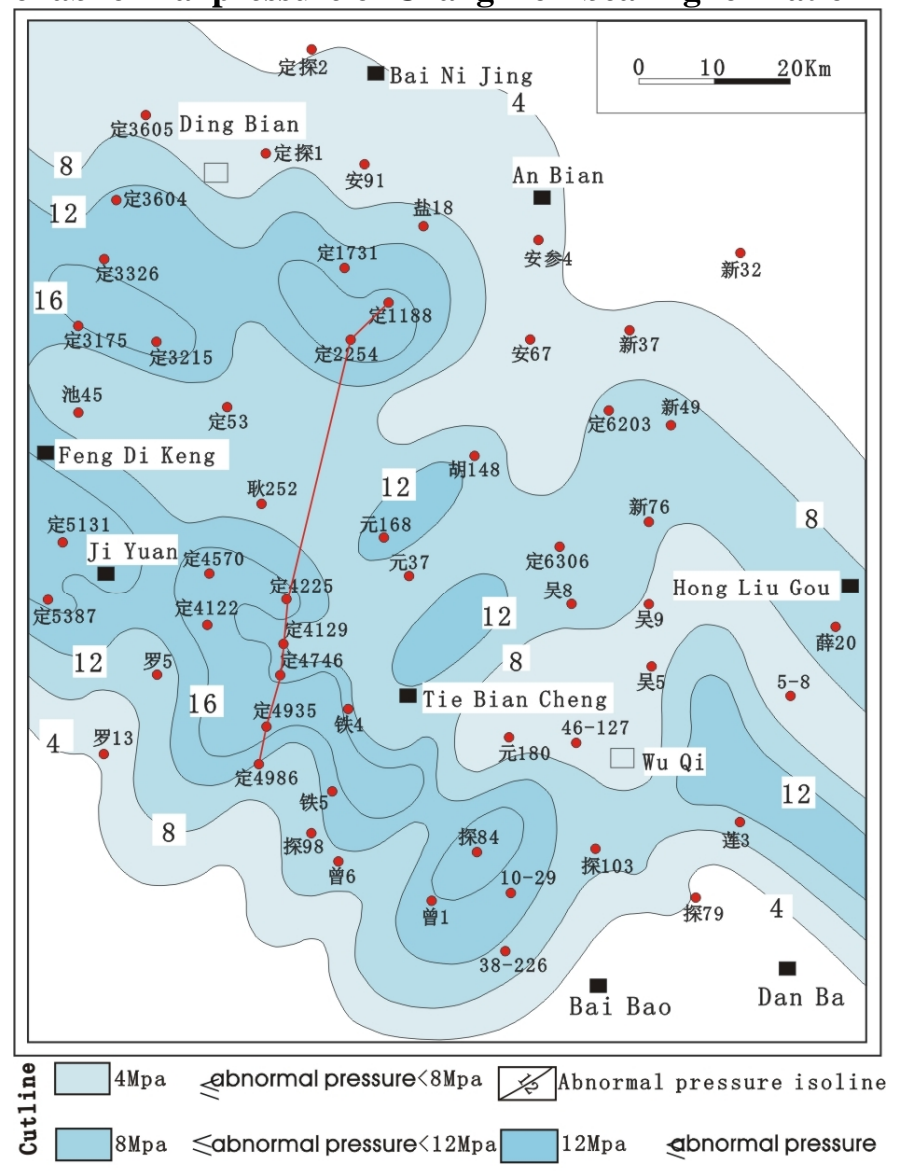

Fig.3 Distribution map of abnormal pressure of Chang 8 oil-bearing formation in the researched region Profile distribution characteristics of Chang 8 and Chang 7 abnormal pressure

Abnormal pressure profiles (Figure 4) study of DING 1188 Well-DING 4986 Wells found that 
Chang 7 is the largest abnormal pressure distribution layer (greater than 20MPa), generally more than $25 \mathrm{MPa}$ and mainly concentrated on the lower part of Chang 7 , which have good continuity, length more than $110 \mathrm{Km}$; abnormal pressure of Chang 8 reservoir group is smaller in the whole, most of region is smaller than the $15 \mathrm{Mpa}$; between Chang 7 reservoir group and Chang 8 reservoir group exists the higher abnormal pressure difference.

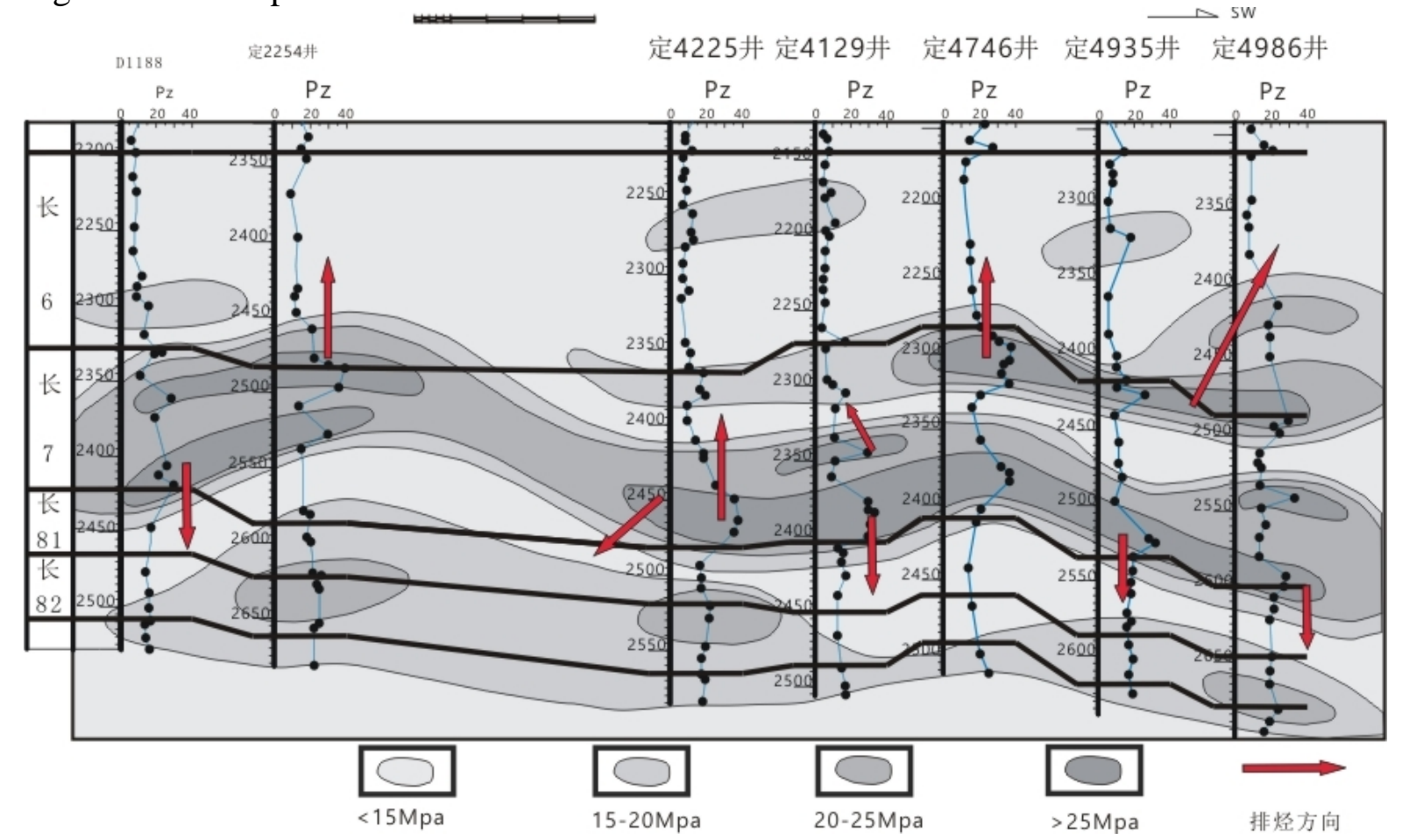

Fig.4 Section map of abnormal pressure from well Ding 1188 to Ding 4986 of Yanchang formation in the researched region ( See Fig. 3 for location )

\section{The relationship between abnormal pressure and hydrocarbon migration \& accumulation of} Chang 7 and Chang 8

\section{The relationship between abnormal pressure and hydrocarbon migration}

Oil and gas migration must have a sufficient accumulation of oil and gas, abnormal pressure for oil and gas provide the impetus from oil-generating strata of the abnormal high pressure migrating into reservoir rock of pore model with neighboring hydrostatic pressure.

Oil layer formation of Chang 7and Chang 8 in the wells of the study area were abnormal pressure (Figure 2,3), oil-bearing formation of Chang7 and oil-bearing formation of lower Chang8 exist universally the higher abnormal pressure difference (Figure 4). Abnormal pressure difference between Chang7 and Chang8 drive for oil and gas of Chang7 hydrocarbon source rocks produced along the micro-cracks from the high potential zone migration to low potential zone. Higher abnormal pressure difference of Chang-7 oil-bearing formation has become the main driving force of oil downward migration, low pressure area of abnormal pressure of Chang- 8 oil-bearing formation or relative low pressure area is trend of oil and gas migration.

\section{The relationship between abnormal pressure and hydrocarbon accumulation}

According to abnormal pressure difference of oil layer formation of Chang 7and Chang 8 in the wells of the study area, the abnormal pressure difference between the two census a map (Figure 5). It can be concluded that oil-bearing formation of Chang7 and lower Chang8 exist universally the higher abnormal pressure difference, most of above of the 4MPa, usually $8-12 \mathrm{MPa}$ or so, some areas of more than $12 \mathrm{MPa}$.

This study combines with reservoir capacity of the lower assemblage of YanChang formation to find better production capacity of Chang8 oil-bearing formation of Zhai zi-he oil zones, Wang Gou-men oil zones, Chang Guan-miao oil zones, southern oil zones of Luohe, Wu Cang-bao oil zones, Fan Xue oil 
zones and five-star village oil zones. More than seven oil zones are shown in Figure 5.

By mean of analyzing abnormal pressure difference of oil-bearing formation of Chang 7 and Chang 8 and known better reservoir location of the lower assemblage of YanChang formation of the study area,It can be concluded that abnormal pressure of the study area and known reservoir distribution is closely related. Most of the reservoir located in high-value areas in the context of low-value of abnormal pressure difference of oil-bearing formation of Chang 7 and Chang 8. (Figure 5).

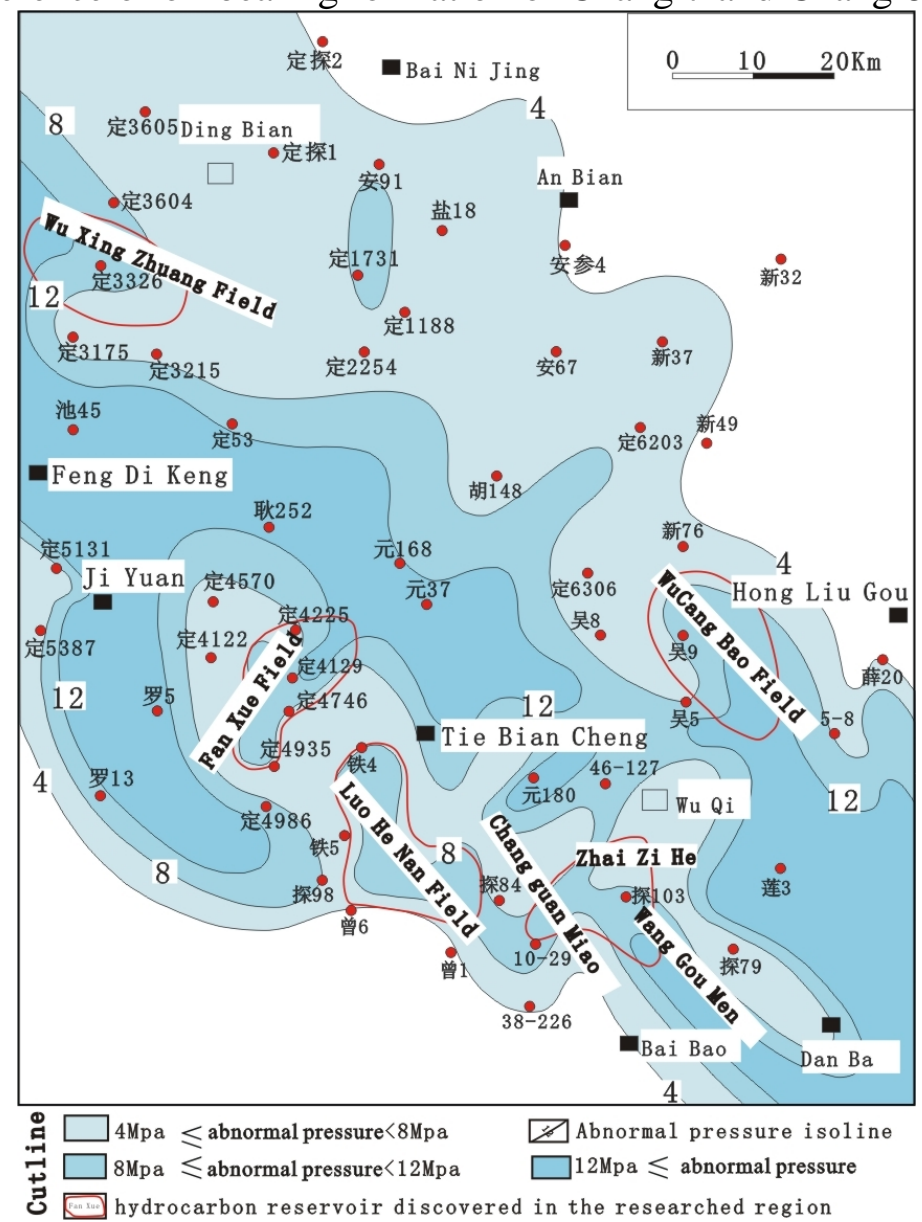

Fig.5 Relational map of hydrocarbon reservoir discovered and difference of abnormal pressure between Chang 7 and Chang 8 in lower assemblage of Yanchang formation of the researched region

\section{conclusions}

The abnormal pressure of Chang 7 is higher than that of Chang 8 oil-bearing formation, which is presented in each well of Chang 7 and Chang 8 oil-bearing formation in the researched region. The difference of abnormal pressure between Chang 7 and Chang 8 , usually about $8 \sim 12 \mathrm{MPa}$, is the principal dynamic power to make the migration of hydrocarbon downward.

The hydrocarbon reservoir discovered is closely relative with the abnormal pressure, most of hydrocarbon reservoirs distribute in areas with high abnormal pressure difference on a background of low abnormal pressure difference between Chang 7 and Chang 8.

\section{Acknowledgements}

This research was supported by the National Basic Research Program of China (973 Program)(No. 2015CB453000), the National Natural Science Foundation of China (No. U1261111). 


\section{References}

[1] Dickinson G.Geological aspects of abnormal reservoir pressures in Gulf Coast Louisiana[J].AAPG Bulletin,1953,37:410-432. Dj.M. Maric, P.F. Meier and S.K. Estreicher: Mater. Sci. Forum Vol. 83-87 (1992), p. 119

[2] Osborne M J,Swarbrick R E.Mechanisms for generating overpressure in sedimentary basins:A reevaluation[J].AAPG Bulletin,1997,81(6):1023-1041.

[3] Luo X R,Dong W L, Yang J H,et al. Overpressuring mechanisms in the Yinggehai basin, south China sea[J].AAPG Bull,2003,87(4):629-645.

[4] Swarbrick R E.AADE forum:Pressure regimes in sedimentary basins and their prediction[J].Marine and Petroleum Geology,1999,16(3):483-486.

[5] Hunt $\mathbf{J}$ M.Generation and migration of petroleum from abnormally pressured fluid compartments[J]:AAPG Bull,1990,74(1):1-12.

[6] JIN Xiaodong, LI Erting, PAN Changchun, et al. Interaction of coal and oil in confined pyrolysis experiments: insight from the yield and composition of gas hydrocarbons[J]. Marine and Petroleum Ueology,2013,48:379-391.

[7] MI Jingkui, ZHANU Shuichang, HE Kun. Experimental investigations about the effect of pressure on gas generation from coal[J]. Organic Ueochemistry,2014,74:116-122.

[8] UCUNA C N, CARR A D, SNAPE C E,et al. High pressure water pyrolysis of coal to evaluate the role of pressure on hydrocarbon generation and source rock maturation at high maturities under geological conditions[J]. Organic Ueochemistry,2015,78;44-51.

[9] UCUNA C N, CARR A D, SNAPE C E, et al.Impact of high water pressure on oil generation and maturation in Kimmeridge Clay and Monterey source rocks: implications for petroleum retendon and gas generation in shale gas systems[J]. Marine and Petroleum Ueology,2016,73:72-85.

[10] WU Yuandong,JI Liming, HE Cong, et al. The ellects of pressure and hydrocarbon expulsion on hydrocarbon generation during hydrous pyrolysis of type-I kerogen in source rock[J]. Journal of Natural Uas Science and Engineering,2016,34; 1215-1224.

[11]Chen Heli and Luo Xiaorong.1988. The quantitative calculation of abnormal fluid pressure in argillaceous and arenaceous rocks and its geological applications.Geological Review, 34(1):54-62. 